B. Sáenz-De San Pedro ${ }^{1}$, M. P. Mur ${ }^{2}$, L. Valverde 3 , M. A. Gonzalo-Garijo ${ }^{4}$, M. Hernandez ${ }^{5}$, B. Madariaga ${ }^{6}$, J. A. Asturias ${ }^{6}$, L. Begoña ${ }^{6}$, A. Martínez ${ }^{6}$, M. C. GÓMEZ-FERNÁNDEZ ${ }^{6}$

\title{
Clinical assessment of tolerability, immunological and cutaneous reactivity effects of an abbreviated schedule with Olea europaea native extract of subcutaneous immunotherapy
}

${ }^{1}$ Jaén University Hospital, Allergology Department, Jaén, Spain

${ }^{2}$ Santa Bárbara Hospital, Allergology Department, Puertollano, Spain

${ }^{3}$ Costa de la Luz Hospital, Allergology Department, Huelva, Spain

${ }^{4}$ Infanta Cristina University Hospital, Allergology Department, Badajoz, Spain

${ }^{5}$ Nisa Hospital, Allergology Department, Seville, Spain

${ }^{6}$ ROXALL España, R\&D Department, Zamudio, Spain

\section{KEY WORDS}

Olea europaea; subcutaneous immunotherapy; rhinoconjunctivitis;

abbreviated schedule; depot extracts.

\section{Corresponding author}

María Cruz Gómez

ROXALL Medicina España S.A.

R\&D Department

Parque Cient. y Tecnol. de Bizkaia

building 401

48170 Zamudio (Bizkaia), Spain

E-mail: maricruz.gomez@roxall.es

\section{Doi}

10.23822/EurAnnACI.1764-1489.124

\begin{abstract}
Summary
Objectives. To evaluate the tolerability and efficacy of Olea europaea subcutaneous immunotherapy (SCIT) on patients with rhinoconjunctivitis. Methods. In this open clinical trial patients were assigned to an abbreviated build-up scheme. The outcomes were: number, percentage, and severity of adverse reactions. Secondary outcomes included: changes in immunoglobulin titers and changes in dose-response skin prick tests. Results. Only 8 systemic reactions were registered, which represented $7 / 47$ (14.9\%) of patients and 8/429 (1.9\%) of administered doses. Regarding immunological parameters the significant increases of $\operatorname{sg} G$ and $\operatorname{sgG} 4$ evidenced the changes in the patient immune system. Cutaneous reactivity decreased significantly. Conclusions. Olea europaea SCIT (Allergovac ${ }^{\circledR}$ depot ROXALL Medicina España S.A.) showed a good safety and tolerability profile. Immunological changes with induction of blocking IgG and decreases in cutaneous reactivity were detected in the patients.
\end{abstract}

List of abbreviations

AEs: Adverse events

AIT: Allergen immunotherapy

AR: Allergic rhinitis

ARs: Adverse reactions

ARIA: Allergic Rhinitis and its Impact on

Asthma

DBU: Diagnostic biological unit

EAACI: European Academy of Allergy and Clinical Immunology

ELISA: Enzyme-Linked Immune Sorbent Assay
$\mathrm{FEV}_{1}$ : Forced expiratory volume in one second

GLP: Good Laboratory Practice

ICH: International Conference on

Harmonisation

ITT: Intention to treat

LR: Local reaction

LTPs: Lipid transfer proteins

MedDRA: Medical Dictionary for

Regulatory Activities

OAS: Oral Allergy Syndrome

PP: Per Protocol
RA: Respiratory Allergy

SCIT: Subcutaneous Immunotherapy

SPT: Skin prick test

sIgE: specific immunoglobulin $\mathrm{E}$

sIgG: specific immunoglobulin $\mathrm{G}$

sIgG4: specific immunoglobulin G4

SLIT: Sublingual immunotherapy

SP: Safety population

SPSS: Statistical Package for Social

Sciences

SR: Systemic reaction

TSU: Treatment standardized unit 


\section{Introduction}

Allergic rhinitis (AR) secondary to olive pollinosis is one of the most important causes of respiratory allergy in the Mediterranean area $(1,2)$. In some provinces of southern Spain, Olea europaea pollen becomes the main allergen overtaking grass and dust mites allergens in eliciting respiratory allergy symptoms (3).

The production of olive pollen extracts may present differences in allergen composition and potency as a result of the variability in cultivars origin (4-6). Some olive tree species like Frantoio, Gordal or Arbequina are less allergenic than Loaime, Hojiblanca or Picual species, regarding immunoblot detection of Ole e 1 (7). These variations could be higher from one batch to another in the case of Ole e 7 and Ole e 9, as a consequence of the little amount of these minor allergens in the source material pollen (8). In addition, these allergenic differences could be affected by external factors in relation to geographical, climatological and pollution conditions where these trees are cultivated; as soil quality, hours of light received, rainfall values and maturation stage of the plant. Thus, the characterization of the olive pollen raw material by manufacturers is crucial during the supplier selection process, in order to assure the presence of these allergens.

It is well known, that olive pollen extracts show a greatly complex and varied allergogram $(9,10)$. Standard laboratory methods have detected at least 20 protein bands with allergenic activity (11). One of the most studied allergens is Ole e 1, it seems to be involved in pollen hydration or germination processes (12). This protein is considered a major allergen, because almost $70 \%$ of allergic patients to Olea europaea recognise it (13). Other olive pollen allergens belong to panallergens family, such as profilin (Ole e 2) (14) and calcium binding proteins (Ole e 3 and Ole e 8 ) (15-17). Ole e 2 is responsible for cross reactivity to vegetable foods and oral allergy syndrome (OAS), and the two latter are related to polysensitization observed with olive pollinosis (9). Ole e 7 belongs to the well-known family of Lipid Transfer Proteins (LTPs) associated with fruit anaphylaxis $(9,18,19)$. In addition, the prevalence of asthma is significantly higher in patients sensitized to Ole e 7 (20). On the contrary, patients sensitized to $1,3-\beta$-gl++ucanase (Ole e 9) have more connection with poor tolerance to allergen immunotherapy and show more severe adverse reactions $(11,21)$.

ROXALL Medicina España S.A. developed a sensitive and specific two-site sandwich ELISA for quantification of Ole e 1 (22). This method is especially useful in manufacturing procedure to guarantee the quality and standardization of allergenic extracts from olive tree pollen, intended for diagnostic and therapeutic clinical use. In addition, the drug substance (Olea europaea allergenic extract) used for manufacturing these products has been characterized and the presence of main olive tree pollen allergens has been detected (Ole e 1, Ole e 2, Ole e 3, Ole e 5,
Ole e 8 , Ole e 9 , Ole e 10, and Ole e 11) by Western-blot and mass spectrometry (ROXALL internal files).

On the other hand, two kind of products are available for SCIT, chemically modified or native allergen extracts. In the most of cases, both of them are absorbed into aluminium hydroxide, in order to reduce the number and severity of systemic adverse reactions by binding and slowly releasing allergens (23). Furthermore, this is the most common adjuvant used in allergen immunotherapy (AIT) (24), being able to induce the immune system response although the mechanism is not fully understood (25). According to European Pharmacopeia, the maximum amount of aluminium (Al) content per human dose is restricted to 1,25 $\mathrm{mg} / \mathrm{mL}$ or lower (26). In spite of the $\mathrm{Al}$ concerns regarding safety and tolerability $(24,27,28)$, until now, there are no major safety issues on limited time SCIT course when the overall load of aluminium is carefully monitored (29).

Traditionally, SCIT depot required large series of injections, which included a long up-dosing phase increasing allergen weekly dose until the achievement of maintenance dose after 3-4 months. Abbreviated schedules, using higher concentrations at the beginning, allowed to shorten this process maintaining a good tolerability profile (30-32). Therefore, an open multicentre clinical trial in adult patients with allergic rhinoconjunctivitis (with or without asthma) using standardized native depot Olea europaea extract was conducted. The main aim of the current clinical trial was to establish the tolerability and safety levels of an abbreviated treatment schedule in patients with allergic rhinoconjunctivitis sensitized to olive tree pollen. Finally, the effects on immunological and cutaneous reactivity were also evaluated.

\section{Materials and methods}

\section{Study design and ethical considerations}

This open, multicentre and phase I clinical trial, was conducted at 5 hospitals in Spain. Patients were assigned to a new abbreviated schedule comprising 6 visits for 5 weeks, where the concentration of the olive pollen extract was increased gradually to reach the target maintenance dose, being the whole treatment duration of 17-weeks (table I). Tolerability was assessed taking into account the number, percentage and severity of adverse reactions and safety, testing haematological and biochemical parameters. The surrogate efficacy was measured through evaluation of immunological parameters and performing skin prick tests (SPTs). The study was conducted in accordance with the principles of the Declaration of Helsinki and the ICH guideline on Good Clinical Practice. It was approved by relevant ethics committees and by the Spanish regulatory authorities, (EudraCT 2014001569-29). Prior to their participation, written informed consent was given by every patient. 
Table I - Treatment schedule.

\begin{tabular}{ccccc}
\hline \multicolumn{5}{c}{ Build up phase treatment schedule } \\
\hline Week & VIAL No & INJECTION VOLUME $(\mathrm{mL})$ & CONCENTRATION (TSU/mL) & DOSE INTERVAL \\
\hline 0 & $\mathbf{2}$ & 0.2 & 50 & NA \\
\hline 1 & $\mathbf{2}$ & 0.5 & 100 & 1 week \\
\hline 2 & $\mathbf{2}$ & 1 & 200 & 1 week \\
\hline 3 & $\mathbf{3}$ & 0.2 & 500 & 1 week \\
\hline 4 & $\mathbf{3}$ & 0.5 & 1000 & 1 week \\
\hline 5 & 1 & Maintenance phase treatment schedule & 1 week \\
\hline Week & VIAL No & INJECTION VOLUME $(\mathrm{mL})$ & CONCENTRATION (TSU/mL) & DOSE INTERVAL \\
\hline 9 & $\mathbf{3}$ & 1 & 1000 & 4 weeks \\
\hline 13 & $\mathbf{3}$ & 1 & 1000 & 4 weeks \\
\hline 17 & 1000 & 4 weeks \\
\hline
\end{tabular}

\section{Study population}

Patients were included in the study if they followed these inclusion criteria: patients aged 18-60 years with seasonal AR due to Olea europaea and clinical history of AR induced by olive tree pollen for at least 2 years prior to the study inclusion. Regarding asthma, only patients with concurrent mild asthma were allowed to participate. A positive SPT against Olea europaea at a concentration of $192 \mu \mathrm{g} / \mathrm{mL}$, (wheal diameter $\geq 3 \mathrm{~mm}$ ) and specific immunoglobulin $\mathrm{E}$ (sIgE) levels $\geq 0.7$ kUA/L determined by ImmunoCAP ${ }^{\circledR}$ (Thermo Fisher Scientific, Uppsala, Sweden) were also required. Women of childbearing age should present a negative urine pregnancy test before first vaccine dose administration.

Patients were excluded from study participation if they had received immunotherapy against Olea europaea or a cross-reactive allergen in the 5 years prior the study inclusion, or if currently they were receiving immunotherapy for any other allergen. In spite of the good control of asthma, patients with moderate to severe asthma and a forced expiratory volume in $1^{\text {st }}$ second $\left(\mathrm{FEV}_{1}\right)<70 \%$, were ineligible. Patients were also excluded if they presented additional clinically relevant sensitization different of Olea europaea or met any of the following criteria: a history of anaphylaxis; chronic urticaria; moderate to severe atopic dermatitis; immunological, cardiac, renal or hepatic diseases; current treatment with immunosuppressants, anti-IgE, tricyclic antidepressants, psychotropic drugs, beta-blockers, or angiotensin-converting enzyme inhibitors and women who were pregnant or breast-feeding.

\section{Study interventions}

A standardized native extract of Olea europaea adsorbed onto $0.2 \%$ aluminium hydroxide, was used for patients' SCIT treatment, (Allergovac ${ }^{\circledR}$ depot, ROXALL Medicina España S.A., Zamudio, Spain). Injections were administered by trained nurses under supervision of qualified allergologists in Immunotherapy Units.

During the first 5-weeks, patients received increasing doses of Olea europaea extract at weekly intervals ( \pm 2 days) to reach the target maintenance dose from the maximum concentration (vial 3, 1000 Treatment Standardized Units (TSU)/mL). The concentration of the major allergen Ole e 1 was $11.28 \mu \mathrm{g} / \mathrm{mL}$. The build-up schedule comprised 6 doses: 3 doses $(0,2,0,5$ and 1 $\mathrm{mL}$ ) from vial $2(100 \mathrm{TSU} / \mathrm{mL})$, and 3 subsequent administrations $(0,2,0,5$ and $1 \mathrm{~mL})$ from vial 3 (table I). Dose modifications were allowed in the event of adverse reactions according to the recommendations of Alvarez-Cuesta et al. (33).

\section{Outcome measures}

Adverse events were collected and recorded for tolerability assessment. As a primary outcome, the incidence of adverse reactions was recorded at Immunotherapy Units during the 30 minutes after each vaccine administration. Likewise, adverse reactions were also collected by checking the patients' diaries designed to register any unpleasant experience outside each participating centres. Adverse reactions were defined as all noxious and unintended responses to any dose of the investigational al- 
lergen vaccine administered. These reactions were classified as immediate (within 30 minutes after the vaccine administration) or delayed (> 30 minutes after vaccine administration).

In the same way, adverse reactions were classified as local (LR, reactions taking place at the arm where vaccine was administered), or systemic (SR, generalised symptoms taking place far away from the administration site). According to LRs extension, we consider clinically significant the immediate $L R \geq 5 \mathrm{~cm}$ and the delayed $L R \geq 10 \mathrm{~cm}$ or those implying a dose modification in the next administration (34). Additionally, LRs were described as diffuse inflammation, redness, erythema, local painfulness, pruritus, or reaction in injection site (when two or more local symptoms took place simultaneously). SRs were classified by the investigators according to the European Academy of Allergy and Clinical Immunology EAACI guidelines (33) and the Medical Dictionary for Regulatory Activities (MedDRA).

Skin prick testing was performed using four increasing concentrations of Olea europaea extract (100, 1,000, 10,000 and 100,000 DBU/mL, Diagnostic Biologic Units) as well as positive (histamine $10 \mathrm{mg} / \mathrm{mL}$ ) and negative (saline) controls. It was performed in one day, by duplicating, in opposing rows in the volar surface of the forearm at basal and final visits. The change in cutaneous reactivity (wheal area in $\mathrm{mm}^{2}$ ) from baseline to the final visit was measured.

Regarding the immunological effects assessment, serum samples were obtained at baseline and final visits to determinate specific immunoglobulin levels (IgE, IgG and $\mathrm{IgG}_{4}$ ) against Olea europaea whole extract by ELISA (Enzyme-Linked Immune Sorbent Assay) as previously described (35). Samples were frozen and sent to ROXALL's central laboratory for bioanalysis in accordance with Good Laboratory Practices (GLPs).

\section{Statistical methods}

We performed tolerability and safety assessment and descriptive statistical analyses in the safety population (patients who received at least one dose of treatment). Efficacy statistical analyses were applied using the intention-to-treat (ITT) population (patients who met all inclusion/exclusion criteria, received at least one dose of treatment and had available data on efficacy variables) and the per-protocol (PP) population (patients who met previous criterial and moreover achieved their target maintenance dose and completed the study without any major protocol deviation).

For descriptive statistics, we displayed categorical variables by absolute and relative frequencies and continuous variables by the standard deviation and the mean.

Changes in immunoglobulin levels and SPT values from baseline to final visit, were analysed by means of the Wilcoxon non-parametric test for paired samples. A bilateral statistical significance level of 0.05 was applied to all statistical tests. Sta- tistical analyses were conducted using the Statistical Package for Social Sciences (SPSS) version 17.

Sample size was calculated considering a percentage of adverse events of $71 \%$ (34). Establishing a confidence interval of $95 \%$ with a precision of \pm 13 percentage unit and assuming a $5 \%$ of drop outs, the number of patients to provide adequate data on the primary endpoint was 49 .

\section{Results}

\section{Descriptive data}

A total of 49 subjects were enrolled in two out-season periods: from $1 / 9 / 15$ to $28 / 2 / 16$ and from $1 / 9 / 16$ to $28 / 2 / 17$. Two of them were screening failures, so 47 ones were assigned to receive AIT and were analysed in safety population (SP). Based on a rigorous clinical history and allergy diagnosis tests, sensitization to Olea europaea was confirmed, therefore, a vaccine of olive tree pollen extract $100 \%$ was indicated. ITT population included 44 patients since 3 patients were excluded due to the absence of data on immunoglobulins or dose-response SPT at final visit. Finally, 42 patients remained in the per protocol population (PP). Major protocol deviations were the reason for the exclusion of 1 patient from this analysis. An additional patient dropped out from the study as a consequence of asthma not related with the treatment by investigator's judgement. Patient's distribution is shown in figure 1. Most patients (70\%) showed

Figure 1 - Study flow chart.

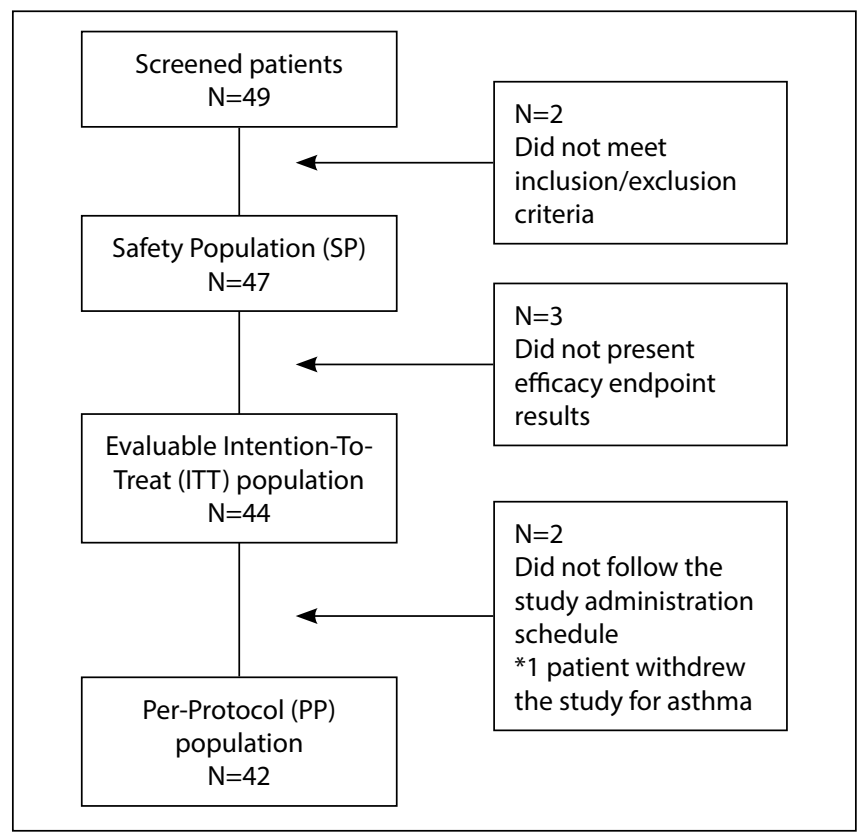

*Patient's disposition along the study. 
sIgE class $\geq 4$ against complete Olea europaea extract. Subjects' baseline demographic and clinical characteristics are presented in table II.

\section{Tolerability and safety}

One hundred and fifty-five adverse events (AEs) were described in the study, being only 37 (23.87\%), related to study vaccine administration. In addition, 31 patients $(66.0 \%)$ reported at least one adverse event (interestingly, one patient reported 17 $\mathrm{AEs})$. The most frequent $\mathrm{AE}$ reported by $>5 \%$ of patients were, headache (23 events in 8 patients, 17.0\%), upper respiratory tract infections (8 events in 7 patients, $14.9 \%$ ), pharyngitis (11 events in 7 patients, $14.9 \%$ ), back pain (17 events in 6 patients, $12.8 \%$ ), cutaneous reaction (11 events in 5 patients, $10.6 \%$ ), dysmenorrhea (7 events in 3 patients, $6.4 \%$ ), myalgia ( 3 events in 3 patients, 6.4\%) and pruritus ( 3 events in 3 patients $6.4 \%$ ). All AEs were non-serious and most of them (82.6\%) were of mild or moderate intensity (mild: symptoms that do not interfere with patients' usual daily activities, moderate: symptoms that interfere in some way with patients' usual daily activities and severe: symptoms that significantly interfere with the sub-

Table II - Patients' baseline clinical characteristics.

\begin{tabular}{lc}
\hline Baseline characteristics & $\begin{array}{c}\text { Abbreviated } \\
\text { schedule }\end{array}$ \\
\hline Number of patients $(\mathrm{SP})^{\mathrm{a}}$ & 47 \\
\hline Age (years), mean $\pm(\mathrm{SD})^{\mathrm{b}}$ & $37.7 \pm 11.82$ \\
\hline Women, $\mathrm{n}(\%)$ & $28(59.6)$ \\
\hline Rhinitis ARIA classification 47 & $0(0)$ \\
\hline Intermittent mild $\mathrm{n}(\%)$ & $0(0)$ \\
\hline Persistent mild n $(\%)$ & $2(4.3)$ \\
\hline Intermittent moderate-severe $\mathrm{n}(\%)$ & $45(95.7)$ \\
\hline Persistent moderate-severe $\mathrm{n}(\%)$ & $27(57.4)$ \\
\hline Main concomitant illness & $9.8 \pm 7.5$ \\
\hline Asthma $\mathrm{n}(\%)$ & $8(17.0)$ \\
\hline Time from diagnostic $($ years $)$, mean \pm SD & $6(12.8)$ \\
\hline IgE Olea europaea CAP class $\mathrm{n}(\%)$ & $16(34.0)$ \\
\hline 2 & $8(17.0)$ \\
\hline 3 & $9.1)$ \\
\hline 4 & \\
\hline 5 & \\
\hline (SP) ${ }^{\mathrm{a}}$ safety population, $(\mathrm{SD})^{\mathrm{b}}$ standard deviation. & \\
\hline
\end{tabular}

ject's usual daily activities). Only 27 (17.4\%) were reported as severe, being headache the most frequent severe $\mathrm{AE}$. In the majority of cases (106) were resolved with symptomatic medication.

During the study period, 5 clinically relevant delayed LR in 5 patients $(10.6 \%)$ were recorded, implying a $1.2 \%$ of the administered doses (table III). There were no immediate clinically relevant LR. Non clinically relevant LR were present in $5.4 \%$ of administered doses.

Regarding systemic reactions, only 8 SRs in 7 patients (14.9\%) were recorded; five grade $0(8.5 \%)$ described as: general discomfort, isolated eye itchy, nasal herpes, lonely oral pruritus and oral pruritus plus nausea. With regards to systemic reactions grade I (2.1\%), only one described as rhinoconjunctivitis was recorded. Finally, two systemic reactions grade II (4.3\%) were documented as generalized urticaria and asthma. There were no systemic reactions grade III or IV. All these SRs occurred during the build-up phase (table III). Systemic reactions represented $1.9 \%$ of the vaccine administrations.

Most of ARs were of mild intensity and took place in the initiation period. Symptomatic treatment or a change in the next administration dose was the most common action required (table III). All patients recovered of the ARs at the end of the study. None of the patients failed to reach the maintenance dose established in the study protocol, in spite of the schedule dose modifications due to 8 adverse reactions.

No clinically relevant changes in blood laboratory parameters were observed following treatment in any patient.

\section{Immunoglobulin levels}

For ITT population, mean changes in immunoglobulin levels against Olea europaea between baseline and final visit are described (figure 2). Statistically significant increases in serum specific IgG and IgG4 titers at final visit were observed compared with basal visit (both $\mathrm{p}<0.001$; Wilcoxon test). Serum specific IgE levels to Olea europaea slightly decreased at final visit, achieving statistical significance $(\mathrm{p}<0.001$; Wilcoxon test). As it was expected, these results were maintained in PP population.

\section{Cutaneous reactivity}

A dose-response SPT was performed with four ten-fold increasing concentrations (vials 1 to 4). Cutaneous reactivity to Olea europaea decreased at final visit compared with baseline values in ITT population. Mean values of wheal area in $\mathrm{mm}^{2}$ were significantly reduced at final visit compared with baseline in each one of the four tested vials (figure 3). Moreover, a statistical significance was achieved with any vial tested ( $p<0.001$; Wilcoxon test from vial 1 to vial 4$)$. These cutaneous results were also reproducible in the PP population. 
Table III - Summary of adverse drug reactions by administration doses ( $N=423$ doses administered).

\begin{tabular}{|c|c|c|c|c|c|c|}
\hline & $\begin{array}{c}\text { Initiation } \\
\text { Phase } \\
\text { n (\%) }\end{array}$ & $\begin{array}{c}\text { Maintenance } \\
\text { Phase } \\
\text { n }(\%)^{*}\end{array}$ & Description & Intensity & Action Taken & Recovery \\
\hline $\begin{array}{l}\text { Clinically relevant } \\
\text { immediate LRs }\end{array}$ & & & Skin reaction ${ }^{\mathrm{a}}$ & mild & dose change & yes \\
\hline \multirow{3}{*}{$\begin{array}{l}\text { Clinically relevant } \\
\text { delayed LRs }\end{array}$} & $4^{a}(0.95)$ & $1^{\mathrm{b}}(0.23)$ & Localized oedema $^{a}$ & mild & dose change & yes \\
\hline & & & Erythema $^{\mathrm{a}}$ & mild & none & yes \\
\hline & & & Injection site reaction ${ }^{\mathrm{b}}$ & severe & dose change & yes \\
\hline \multicolumn{7}{|l|}{ Systemic reactions } \\
\hline & & & General discomfort $^{c}$ & mild & none & yes \\
\hline Grade $0^{c}$ & & & Pruritus + nausea ${ }^{c}$ & moderate & none & yes \\
\hline \multirow[t]{2}{*}{ Grade $I^{d}$} & $1(0.2)$ & - & Rhinoconjunctivitis $^{\mathrm{d}}$ & moderate & none & yes \\
\hline & & & Asthma ${ }^{e}$ & severe & change + treatment & yes \\
\hline Grade II $^{\mathrm{e}}$ & $2(0.5)$ & -- & Urticaria $^{\mathrm{e}}$ & mild & change + treatment & yes \\
\hline
\end{tabular}

Figure 2 - Changes in specific Olea europaea pollen extract immunoglobulins.

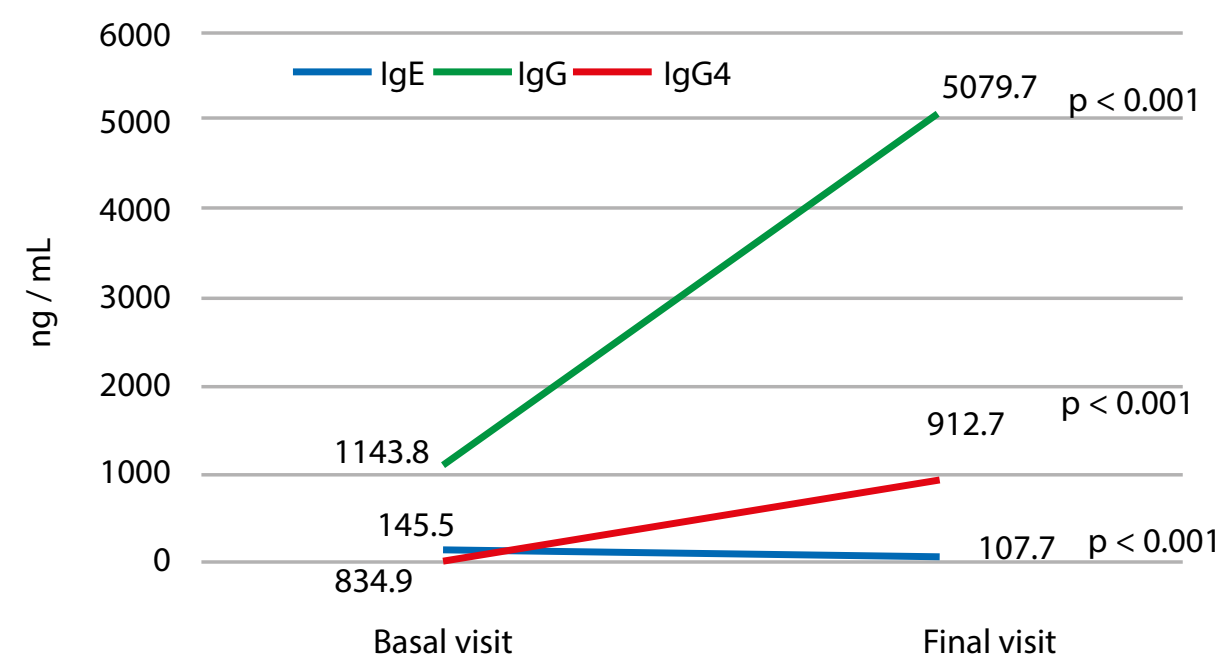

Specific Olea europaea pollen extract immunoglobulins. Corresponding P-values according to Wilcoxon test are indicated. 
Figure 3 - Change in mean wheal area at final visit versus baseline to Olea europaea.

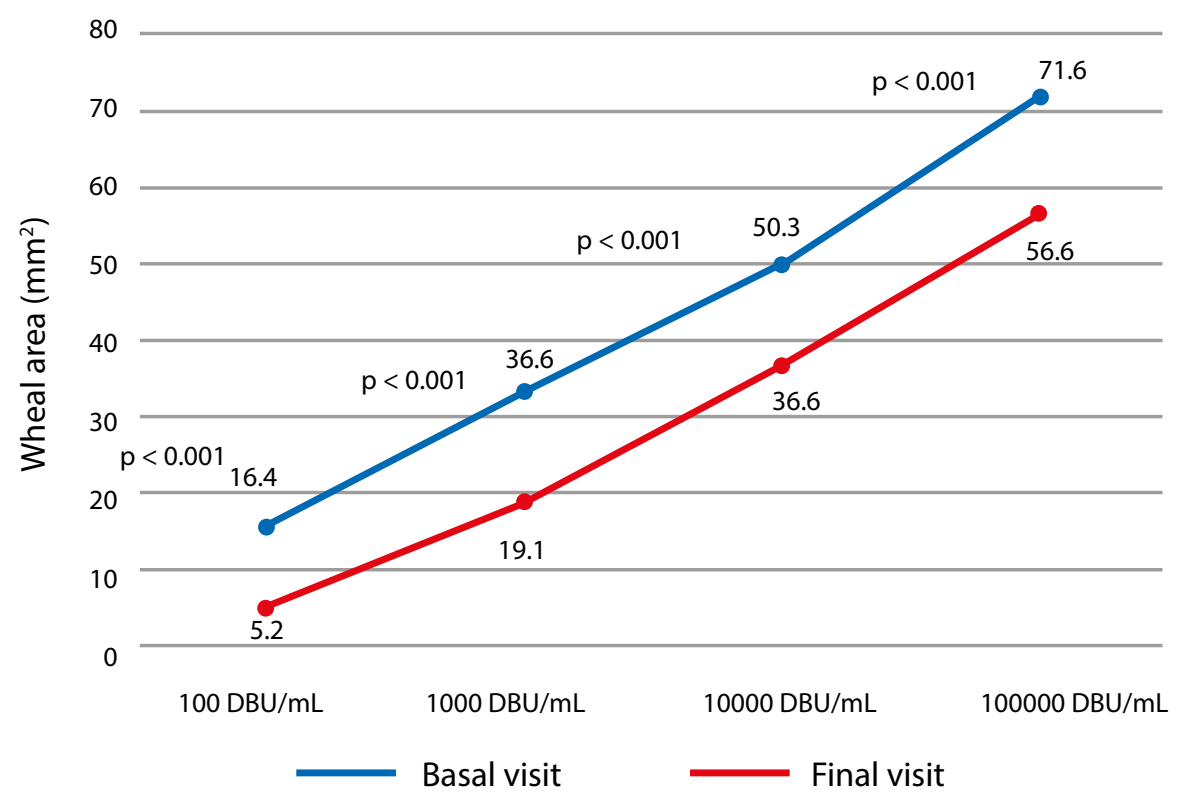

\section{Discussion}

In Mediterranean countries and especially in provinces of southern Spain (Córdoba and Jaén), rhinoconjunctivitis due to olive tree pollen is one of the most frequent consultations to allergologist (36). It is also a health problem due to the large surface area devoted to this crop in Andalusia (37).

Allergen-specific immunotherapy is the unique etiologic treatment that can alter the course of the respiratory allergy condition, presenting a disease modifying effect and inducing tolerance to the antigen (38). Traditionally, clinicians prescribed allergy immunotherapy following two defined schedules as perennial or pre-seasonal. The first one was generally used in respiratory allergy secondary to perennial allergens, (i.e. mites and moulds) while the pre-seasonal schedule was usually preferred in pollinosis. Both immunotherapy schedules have been shown to be effective in terms of clinical and immunological parameters (39). Currently, perennial schedules are more commonly used in AIT clinical practice with independency of the kind of the allergen responsible. Pre-seasonal and co-seasonal schedules are more frequently used in sublingual immunotherapy (SLIT) (40). In the event of performing a perennial subcutaneous schedule with pollen allergens, it is recommended to carry out the scale up outside the pollen season to diminish the risk of adverse reactions. Not only for the effect of the induction phase, which is related to a significantly higher number of systemic reactions (40), but also for the "priming effect," due to the natural exposure to a high amount of grain pollens. Consequently, the vaccine tolerance can be reduced, because of these two factors (41). On the other hand, classic AIT comprises a build-up phase with increasing doses of allergen extracts administered at short regular intervals until the optimal dose is reached. Afterwards, a maintenance period where the optimal dose is administered approximately at monthly intervals for 3 to 5 years is performed. According to the initial increasing doses schedule, immunotherapy is categorized as rush, cluster, abbreviated and conventional. Conventional schedules implies that maintenance dose is achieved after a long period of time, between 2-3 months (42). The modern tendency is to provide a treatment schedule that allows the attainment of the maintenance dose in the shortest period with the fewest adverse events and the best patient adherence to treatment. For these reasons, the abbreviated schedule can be considered a good AIT option. A potential risk of fast schedules (rush, accelerated and abbreviated) is an increase in adverse reactions, especially systemic ones (42), although in other published article, an accelerated schedule versus a conventional one with grass SCIT seems to be similar between both regimens (43). The pattern and intensity of adverse reactions in our trial were similar to those reported in other studies, in spite of the difficulties to com- 
pare trials due to the differences in the products (44-46). The maintenance dose of $1000 \mathrm{TSU} / \mathrm{mL}$ was reached by all study participants. Only 8 systemic reactions in 7 patients (14.9\%) and $1.9 \%$ of administered doses were recorded and no one was grade III or higher. A randomized unblinded controlled study with SCIT containing a standardized extract of Olea europaea reported good clinical results in nasal and bronchial symptoms with a rate of systemic reactions in $8.7 \%$ of the patients (44). Another open label clinical trial (45) with 93 patients treated with a short up-dosing SCIT containing Olea europaea extract, showed a slightly lower rate of systemic reactions $4.3 \%$. However, non-specific or grade 0 reactions were not taken into consideration for the analysis. Other multicentre randomized clinical trials evaluated the tolerability of two five-step up-dosing schedules for SCIT with grasses. The incidence of systemic adverse reactions was $22.5 \%$ for group 1, (weekly injections) and $35.1 \%$ in group 2, (3-4 days interval injection), according to Jung K. (31), and $21 \%$ and $33 \%$ of patients in group 1 and group 2 respectively, according to Pfaar O. (32).

Regarding to the early immunological response produced by the new up-dosing SCIT depot formulation, in five steps, it could be confirmed the statistically significant increment of more than 4-fold for $\operatorname{sigG}(\mathrm{x} 4.4)$ and more than 6-fold for sIgG4 (x6.3) levels to Olea europaea, after 3 months of therapy. Similar results could be observed in other studies, where a rapid increase in $\operatorname{sgG}$ and $\operatorname{sgG} 4$ can be associated with the effect of blocking IgE-binding to allergens and B cells $(39,45,46)$. In spite of the fact that sIgE levels after a short course of AIT, cannot always present the same behavior depending on analytical technique (47), our immunological results, measured using the ELISA technique at the Protein Lab of ROXALL Medicina España S.A. (48), showed a very early decreased which are in line with results published in other bibliography references (48-53).

With respect to cutaneous reactivity to the causative allergen, a statistically significant reduction in immediate skin reactivity to the different concentrations of Olea europaea extract was observed, expressed as a decrease in the mean wheal area produced by each concentration tested. This result is in the line of another clinical trial (45) with an extract of Olea europaea after a short course of AIT.

Since the main objective of this study was tolerability, the trial was designed without a placebo group. This fact must be taken into account when interpreting the reported surrogate efficacy results because the comparison was made with each patient comparing with himself.

\section{Conclusions}

The results of this clinical trial show that the build-up phase and the maintenance phase assayed up to 17 weeks with this abbreviated schedule with native depot Olea europaea SCIT, (Allergovac ${ }^{\circledR}$ depot ROXALL Medicina España), have a good tolerability profile, with few systemic and local clinically significant reactions. In addition, the treatment induces a surrogate positive efficacy response. This fact is confirmed by significant immunological and cutaneous reactivity changes in subjects suffering from allergic rhinoconjunctivitis with or without asthma due to sensitization to olive pollen. In spite of these good preliminary results, the reduction of rhinoconjunctivitis symptoms remains to be demonstrated in further clinical trials.

\section{Acknowledgements}

The authors would like to thank participating hospitals and the inestimable help of all collaborator investigators like: Arantza Martín Iglesias, Remedios Pérez-Calderón and Elena Bonet.

Blanca Sáenz-De San Pedro, María Pilar Mur, Lucía Valverde, María Angela Gonzalo-Garijo and Mercedes Hernández are the sites principal investigators disposed according to highest recruitment. María Cruz Gómez-Fernández was the sponsor's designated project manager and drafted the manuscript. Juan Andrés Asturias was responsible of the immunological analysis blood samples Begoña Madariaga, Leire Begoña and Alberto Martínez contributed in the conception, design, development, data analysis, data interpretation, drafting of the manuscript and manuscript revision.

\section{Fundings}

This study was supported in totally by ROXALL Medicina España S.A.

\section{Conflict of interests}

Blanca Saenz-De San Pedro has received research fees from ALK- Abello, Leti, Novartis, Diater, Meda, Shire and Bial. María Pilar Mur has received research fees from ALK- Abello, Leti, Diater, GSK, Chiesi, Astra and Roxall. Lucía Valverde has received collaboration fees from ALK- Abello. María Angela Gonzalo-Garijo has received collaboration fees from ALK-Abelló, Allergy Therapeutics, Bial/Roxall, Diater, Leti, Merck-Allergopharma and Stallergenes. Begoña Madariaga, Juan Andrés Asturias, Leire Begoña, Alberto Martínez and $M^{\mathrm{a}}$ Cruz Gómez are fulltime employees of ROXALL Medicina España S.A. Mercedes Hernández has no conflicts of interest to declare. The authors have no other relevant affiliations or financial involvement with any organization or entity with a financial interest in or financial conflict with the subject matter or materials discussed in the manuscript apart from those disclosed. 


\section{References}

1. D'Amato G, Liccardi G. The increasing trend of seasonal respiratory allergy in urban areas. Allergy 2002;57 (suppl 71):35-6.

2. Nikolaidis C, Katotomichelakis M, Nena E, Makris M, Tsakas M, Michopoulos I, Constantinidis TC and Danielides V. Seasonal variations of allergenic pollen in a Mediterranean region - Alexandroupolis, north-east Greece. Ann Agric Environ Med 2015;22(4):685-9.

3. Domínguez-Ortega J, Quirce S, Delgado J, Dávila I, Martí-Guadaño $E$ and Valero A. Diagnostic and therapeutic approaches in respiratory allergy are different depending on the profile of aeroallergen sensitisation. Allergol Immunopathol (Madr) 2014;42(1):11-8.

4. Alché JD, Castro AJ, Jiménez-lópez JC, Morales S, Zafra A, Hamman-khalifa AM and Rodríguez-García MI. Differential characteristics of olive pollen from different cultivars: biological and clinical Implications. J Investig Allergol Clin Immunol 2007; 17 Suppl1: 69-75.

5. Conde Hernández J, Conde Hernández P, Gónzalez Quevedo Tejerína MT, Conde Alcañiz MA, Conde Alcañiz EM, Crespo Moreira $\mathrm{P}$, Cabanillas Platero M. Antigenic and allergenic differences between 16 different cultivars of Olea europaea. Allergy 2002;57 Suppl 71:60-5.

6. Barber D, Carpizo J, Garcia-Rumbao MC, Polo F, and Juan F. Allergenic variability in Olea pollen. Ann Allergy 1990;64(1):43-6.

7. Castro JA, de Dios Alché J, Cuevas J, Romero PJ, Alché V and Rodríguez-García MI. Pollen from different olive tree cultivars contains varying amounts of the major allergen Ole e 1. Int Arch Allergy Immunol 2003;131(3):164-73.

8. Barber D, Moreno C, Ledesma A, Serrano P, Galán A, Villalba M, Guerra F, Lombardero $M$ et al. Degree of olive pollen exposure and sensitization patterns. Clinical implications. J Investig Allergol Clin Immunol 2007;17(Suppl 1):63-8.

9. Quiralte J, Palacios L, Rodríguez R, Cárdaba B, Arias de Saavedra JM, Villalba M, Florido JF and Lahoz C. Modelling diseases: the allergens of Olea europaea pollen. J Investig Allergol Clin Immunol 2007;17 (Suppl 1):24-30.

10. Rodríguez R, Villalba M, Batanero E, Palomares O, Quiralte J, Salamanca G, Sirvent S, Castro L et al. Olive pollen recombinant allergens: value in diagnosis and immunotherapy. J Investig Allergol Clin Immunol 2007;17(Suppl 1):56-62

11. Villalba M, Rodríguez $\mathrm{R}$ and Batanero E. The spectrum of olive pollen allergens. From structures to diagnosis and treatment. Methods 2014;66(1):44-54.

12. Tang W, Ezcurra I, Muschietti J and McCormick S. A cysteine-rich extracellular protein, LAT52, interacts with the extracellular domain of the pollen receptor kinase LePRK2. Plant Cell 2002;14(9):2277-87.

13. Palomares O, Swoboda I, Villalba M, Balic N, Spitzauer S, Rodríguez R, Valenta R. The major allergen of olive pollen Ole e 1 is a diagnostic marker for sensitization to Oleaceae. Int Arch Allergy Immunol 2006;141(2):110-8.14.

14. Ledesma A, Rodríguez R and Villalba M. Olive-pollen profilin. Molecular and immunologic properties. Allergy.1998;53(5):520-6.

15. Quiralte J, Florido F, Arias de Saavedra JM, Gómez A, Sáenz de San Pedro B, González E, and Rodríguez R. Olive allergen-specific $\mathrm{IgE}$ responses in patients with Olea europaea pollinosis. Allergy 2002;57 (Suppl 71):47-52.

16. Batanero E, Villalba M, Ledesma A, Puente XS and Rodríguez R. Ole e 3, an olive-tree allergen, belongs to a widespread family of pollen proteins. Eur J Biochem 1996;241(3):772-8.
17. Ledesma A, Villalba $M$ and Rodríguez R. Cloning, expression and characterization of a novel four EF-hand Ca2+-binding protein from olive pollen with allergenic activity. FEBS Lett 2000;466(1):192-6.

18. Florido López JF, Quiralte Enriquez J, Arias de Saavedra Alías JM, Sáenz de San Pedro B, Martín Casañez E. An allergen from Olea europaea pollen (Ole e 7) is associated with plant-derived food anaphylaxis. Allergy 2002;57(Suppl 71):53-9.

19. Scala E, Abeni D, Pomponi D, Paganelli R, Locanto M, Giani M, Cecchi L and Asero R. Ole e 1, Ole e 7, and Ole e 9: Identifying distinct clinical subsets of olive tree-allergic patients. J Allergy Clin Immunol 2016;137(2):629-31.

20. Alcántara M, Sáenz de San Pedro B, Cañada C, Muñoz MA, Jimeno L, Villalba M and de la Torre F. Steps towards clarifying the clinical relevance of minor olive allergens in areas with extremely high levels of olive pollen. J Investig Allergol Clin Immunol 2017;27(2):138-140.

21. Duffort O, Palomares O, Lombardero M, Villalba M, Barber D, Rodríguez R and Polo F. Variability of Ole e 9 allergen in olive pollen extracts: Relevance of minor allergens in immunotherapy treatments. Int Arch Allergy Immunol 2006;140(2):131-8.

22. Arilla MC, Eraso E, Ibarrola I, Algorta J, Martínez A and Asturias JA. Monoclonal antibody-based method for measuring olive pollen major allergen Ole e 1. Ann Allergy, Asthma Immunol 2002;89(1):83-9.

23. Hogenesch H. Mechanism of immunopotentiation and safety of aluminum adjuvants. Front Immunol 2013;3:406.

24. Kramer MF and Heath MD. Aluminium in allergen-specific subcutaneous immunotherapy - A German perspective. Vaccine 2014;32(33):4140-8.

25. Klimek L, Schmidt-Weber CB, Kramer MF, Skinner MA and Heath MD. Clinical use of adjuvants in allergen-immunotherapy. Expert Rev Clin Immunol 2017;13(6):599-610.

26. EMA, Agency, Medicines E. CHMP Safety Working Party 's response to the PDCO regarding aluminium hydroxide contained in allergen products. EMA J 2010;44.

27. Jensen-Jarolim E. Aluminium in Allergies and Allergen immunotherapy. World Allergy Organ J 2015;8(1): 7.

28. Guimarães LE, Baker B, Perricone C and Shoenfeld Y. Vaccines, adjuvants and autoimmunity. Pharmacol Res. 2015;100:190-209.

29. Gołoś A and Lutyńska A. Aluminium-adjuvanted vaccines-A review of the current state of knowledge. Przegl Epidemiol. 2015;69(4):731-4.

30. Bousquet J, Calvayrac P, Guérin B, Hejjaoui A, Dhivert H, Hewitt $\mathrm{B}$ and Michel FB. Immunotherapy with a standardized Dermatophagoides pteronyssinus extract. I. In vivo and in vitro parameters after a short course of treatment. J Allergy Clin Immunol 1985;76(5):734-44.

31. Jung K. Safety and tolerability of immunotherapy using various updosing schedules of a new SCIT product with an optimised allergen/aluminium hydroxide ratio. Allergy Eur J Allergy Clin Immunol 2011;66(suppl 95):41-3.

32. Pfaar O, Jung K, Wolf H, Decot E, Kleine-Tebbe J, Klimek L and Wüstenberg E. Immunological effects and tolerability of a new fast updosed immunologically enhanced subcutaneous immunotherapy formulation with optimized allergen/adjuvant ratio. Allergy 2012;67(5):630-7.

33. Alvarez-Cuesta E, Bousquet J, Canonica GW, Durham SR, Malling HJ and Valovirta E. EAACI, Immunotherapy Task Force. Standards for practical allergen-specific immunotherapy. Allergy. 2006;61 (Suppl 82):1-20. 
34. Casanovas M, Sastre J, Fernandez-Nieto M, Lluch M, Carnés J and Fernández-Caldas E. Double-blind study of tolerability and antibody production of unmodified and chemically modified allergen vaccines of Phleum pratense. Clin Exp Allergy 2005;35 (10):1377-83

35. Sola J, Sánchez V, Landeta A, Madariaga B, Martínez A and Álvarez-Cuesta E. A phase I clinical trial with subcutaneous immunotherapy vaccine of Timothy grass pollen extract according to EMA guidelines. Immunotherapy 2015;7(4):343-52.

36. Sociedad Española Alergia e Inmunología Clínica SEAIC (Ed.). Alergologica 2015. Factores epidemiológicos, clínicos y socioeconómicos de las enfermedades alérgicas en España en 2015, 2015th Edition. Draft Grupo de Comunicación Healthcare, Madrid, Spain 2015; 1-352.

37. Vázquez LM, Galán C and Domínguez-Vilches E. Influence of meteorological parameters on Olea pollen concentrations in Córdoba (south-western Spain). Int J Biometeorol 2003;48(2):83-90.

38. Shamji MH and Durham SR. Mechanisms of allergen immunotherapy for inhaled allergens and predictive biomarkers. J Allergy Clin Immunol 2017;140(6):1485-98.

39. Gokmen NM, Ersoy R, Gulbahar O, Ardeniz O, Sin A, Unsel $\mathrm{M}$ and Kokuludag A. Desensitization effect of preseasonal seven-injection allergoid immunotherapy with olive pollen on basophil activation: the efficacy of olive pollen-specific preseasonal allergoid immunotherapy on basophils. Int Arch Allergy Immunol 2012;159(1):75-82.

40. Calderón MA, Vidal C, Rodríguez Del Río P, Just J, Pfaar O, Tabar AI, Sánchez-Machín I, Bubel P, Borja J, Eberle P, Reiber R, Bouvier M, Lepelliez A, Klimek L, Demoly P and EASSI Doctors' Group. European Survey on Adverse Systemic Reactions in Allergen Immunotherapy (EASSI): a real-life clinical assessment. Allergy 2017;72(3):462-472.

41. Pfaar O, Wolf H, Klimek L, Schnitker J and Wüstenberg E. Immunologic effect and tolerability of intra-seasonal subcutaneous immunotherapy with an 8-day up-dosing schedule to 10,000 standardized quality-units : a double-blind, randomized, placebo-controlled trial. Clin Ther 2012;34(10):2072-81.

42. Serrano P, Justicia JL, Sánchez C, Cimarra M, Fernández-Távora L, Orovitg A, Moreno C, Guerra F, et al. Systemic tolerability of specific subcutaneous immunotherapy with index-of-reactivity - standardized allergen extracts administered using clustered regimens : a retrospective, observational, multicenter study. Ann Allergy Asthma Immunol 2009;102(3):247-52.

43. Pfaar O, van Twuijver E, Hecker H, Boot JD, van Ree R and Klimek L. Accelerated up-dosing of subcutaneous immunotherapy with a registered allergoid grass pollen preparation. Int Arch Allergy Immunol 2013;160(4):420-4.

44. González P, Florido F, Sáenz de San Pedro B, de la Torre F, Rico $\mathrm{P}$ and Martín S. Immunotherapy with an extract of Olea europaea quantified in mass units. Evaluation of the safety and efficacy after one year of treatment. J Investig Allergol Clin Immunol 2002;12(4):263-71.
45. Moreno C, Sáenz de San Pedro B, Millán C, Panizo C, Martín $S$, Florido F. Exploratory study of tolerability and immunological effect of a short up-dosing immunotherapy phase with a standardised allergen extract derived from pollen of Olea europaea. Clin Transl Allergy 2015;24(5):1-6.

46. Macchia L, Caiaffa MF, Di Felice G, Pini C, Bariletto G, Strada $S$ and Tursi A. Changes in skin reactivity, specific $\operatorname{IgE}$ and $\operatorname{IgG}$ levels after one year of immunotherapy in olive pollinosis. Allergy 1991;46(6):410-8.

47. Lawrence MG, Steinke JW, Borish L. Basic science for the clinician: Mechanisms of sublingual and subcutaneous immunotherapy. Ann Allergy Asthma Immunol 2016;117(2):138-42.

48. Sola J, Sánchez V, Landeta A, Madariaga B, Martínez A, Álvarez-Cuesta E. A Phase I clinical trial with subcutaneous immunotherapy vaccine of Timothy grass pollen extract according to EMA guidelines. Immunotherapy 2015;7(4):343-52.

49. Quiralte J, Lara MA, Sánchez GV, Monteserín J, Fernández L, Gómez-Fernández MC, Madariaga B, Arilla C, Asturias JA, Begoña L, Martínez A. Tolerability and surrogate efficacy parameters of a polymerized depot mixture pollen extracts without dilutional effect. Immunotherapy 2019 Aug; 11(12):1031-42.

50. Enrique E, de Rojas DH, Alba P, Flores I, Colomer N, Andreu C, Gómez-Fernández MC, Landeta A, Asturias JA, Martínez A, Madariaga-Goirigolzarri B. Tolerability and positive efficacy results after subcutaneous immunotherapy with Parietaria judaica depot extract. Immunotherapy 2018 Oct;10(14):1253-63.

51. Moreno V, Alvariño M, Rodríguez F, Roger A, Peña-Arellano MI, Lleonart R, Pagán JA, Navarro JA, Navarro LA, Vidal C, Ponte-Tellechea A, Gómez-Fernández MC, Madariaga-Goirigolzarri B, Asturias JA, Hernández-Fernandez de Rojas D. Randomized dose-response study of subcutaneous immunotherapy with a Dermatophagoides pteronyssinus extract in patients with respiratory allergy. Immunotherapy 2016;8(3):265-77.

52. Sola J, da Silva Ferreira JA, Dionicio Elera J, Plácido JL, Pereira C, Fonseca J, Panizo C, Inácio LF, Cancelleire N, Zubeldia Ortuño JM, Landeta A, Madariaga B, Martínez A. Timothy grass pollen therapeutic vaccine: optimal dose for subcutaneous immunotherapy. Immunotherapy 2016;8(3):251-63.

53. Hernández Fernández de Rojas D, Antépara Ercoreca I, Ponte Tellechea A, Ibáñez Echevarría E, Jáuregui Presa I, Gamboa Setién P, Asturias JA, Landeta Manzano A, Madariaga Goirigolzarri B. Phase I study of subcutaneous allergen immunotherapy with Dermatophagoides pteronyssinus in patients with allergic rhinoconjunctivitis with or without asthma. Immunotherapy 2015;7(2):89-99.

54. Brozek JL, Bousquet J, Baena-Cagnani CE, Bonini S, Canonica GW, Casale TB, van Wijk RG, Ohta K, Zuberbier T, et al. Global Allergy and Asthma European Network; Grading of Recommendations Assessment, Development and Evaluation Working Group. Allergic Rhinitis and its Impact on Asthma (ARIA) guidelines: 2010 revision. J Allergy Clin Immunol 2010;126(3):466-76. 